\title{
SIDA E HOMOSSEXUALIDADE EM ÚLTIMA PARAGEM MASSAMÁ
}

\author{
Monalisa Almeida Cesetti Gomyde ${ }^{1}$
}

Resumo: A partir das elaborações desenvolvidas por Susan Sontag em seus dois textos essenciais, $A$ doença como metáfora (1978) e AIDS e suas metáforas (1989), esse artigo tenciona compreender a função metafórica, ética e estética da aids no romance Última Paragem Massamá (2011), do escritor português Pedro Vieira, concentrando-se na reflexão acerca da homossexualidade e da homoafetividade e sua relação com a aids dentro da narrativa.

Palavras-Chave: Sexualidade. Ficção Portuguesa Contemporânea. Pedro Vieira. Última paragem Massamá.

\section{AIDS AND HOMOSSEXUALITY IN ÚLTIMA PARAGEM MASSAMÁ}

\begin{abstract}
Based on the elaborations developed by Susan Sontag in her two essential texts, Illness as a metaphor (1978) and AIDS and its metaphors (1989), this article intends to understand the metaphorical, ethical and aesthetic functions of aids in the novel Última Paragem Massamá (2011) by the Portuguese writer Pedro Vieira, focusing on the considerations about homosexuality and its relationship with aids within the narrative.
\end{abstract}

Keywords: Sexuality. Contemporary Portuguese Fiction. Pedro Vieira. Última paragem Massamá.

Estou aqui a pensar num homem, meu Deus?

(Pedro Vieira, 2011, p. 114)

[...] este é um relato (retrato) de e para a família

(Pedro Vieira, 2011, p. 87)

A ligação entre cultura e doença é um tema corrente das produções humanas. O impulso para não só representar, mas, até mesmo, solucionar o mistério do adoecimento físico, da morte e da susceptibilidade do corpo, não se contenta apenas com explicações científicas. Nesse sentido, tanto aqueles que sofreram adoecimentos, como os que encontraram na representação da

\footnotetext{
${ }^{1}$ Bacharela em Estudos Literários pela UNICAMP e mestranda do Programa de Pós-Graduação em Literatura pela UFSCAR. E-mail: monalisagomyde@gmail.com.
} 
doença a possibilidade de criação de figuras, analogias e metáforas potentes o suficiente para abarcar outros fenômenos, utilizam da ficcionalização do adoecimento como ferramenta na busca por sentido ou de denúncia da falta dele. Quanto maior o mistério, isto é, a falta de respostas científicas acerca de uma doença, mais potente é o poder metafórico dela (SONTAG, 1978, p. 6). O mistério permite que as representações da doença - que por si só já se presta à imagem daquilo fora-de-lugar, fora da normalidade da saúde e dos saudáveis sejam a tal intensidade resultado dos valores de determinada sociedade, que continuam funcionando como uma janela através da qual é possível examinar um povo e sua cultura, mesmo após a desmistificação operada pela ciência. Logo, a doença se mostra tema prolífico para a produção literária e também para sua crítica. Como aponta Carlos Roberto Da Silva,

Ao se pensar as representações sociais da doença, percebe-se um deslocamento da doença como fato para a doença como experiência, provocando o imbricamento das dimensões social e individual do ato de adoecer, em que doente e adoecimento são, já, categorias sociais. [...] a imersão em narrativas ficcionais com o propósito de compreender as funções - evidentemente complexas das representações sociais, especificamente das doenças, em nossa sociedade, permite também, ao interpretar as alegorias do discurso literário, compreender de forma mais profunda a construção dessa mesma sociedade (DA SILVA, 2006, p. 35).

Por sua vez, representações das sexualidades e do sexo, especialmente da homossexualidade, apesar das tentativas de explicações pela via biológica, sempre estiveram ancoradas no campo da cultura, pois é nesse âmbito que práticas são simbolicamente projetadas, identidades são cunhadas e o discurso se alimenta de e alimenta a percepção e caracterização daquilo que hoje entende-se como orientação sexual. Relações afetivo-sexuais entre pessoas do mesmo sexo sempre existiram, mas a maneira como foram compreendidas e representadas diverge ao longo do tempo e localidade. É apenas no século XIX que o homossexual enquanto figura social surge, compreendido desde o modelo higienista dentro de um campo médico-legal (TONIETTE, 2006, p. 44). Desde então, a identidade homossexual permanece 
em constante plasticidade, sendo definida e redefinida em diversas esferas da sociedade tanto por aqueles que a habitam como por aqueles que produzem discursos e práticas de violência contra os homossexuais. Tornando esse tema uma janela também particularmente poderosa pela qual se olhar o mundo, produzir e ler literatura.

No romance do até então blogueiro e artista gráfico, Pedro Vieira, publicado em 2011 e agraciado em 2012 com o Prémio PEN Clube Português para Primeira Obra, Última Paragem Massamá, a leitora se encontra com a história de um trajeto e das pessoas que o percorrem. O trajeto é a linha de Sintra e os muitos personagens são os passageiros do trem. Dentre esses, encontram-se os três que compõem o núcleo principal da narrativa: Vanessa, Lucas e João. Vanessa, jovem mulher com um passado complicado, do qual não traz nenhuma segurança, senão desamparos, conhece Lucas no Centro de Emprego. Lucas, homem por volta de seus quarenta anos trabalha no Centro de Emprego e vive em Massamá, conhece Vanessa, formam um casal. Finalmente, João, homem declaradamente homossexual, trabalha em um banco e vive uma vida de romances fugidios, pelo qual Lucas se apaixona pode-se dizer isso? - e com quem passa a ter um relacionamento nem tão secreto. Logo no início da trama sabemos o desfecho, Vanessa se joga na linha do trem à la Anna Karênina, pois Lucas a deixara sozinha. Ainda não sabemos que quem lhe roubou Lucas não foi João, mas a SIDA².

Esse é um romance no qual os sentimentos e pensamentos das personagens irrompem no texto em lapsos. A trama se desenrola nos espaços de forma um tanto quanto episódica, criando uma sensação de quebra constante na qual as narrativas dos passantes se cruzam, se cortam e se atravancam e não há tempo para aquilo que cada uma pensa e sente ser explorado. Há personagens dos quais no início espera-se algum desenvolvimento, mas eles surgem e somem, o que permanece é o espaço, a linha de Sintra, suas paradas e sua natureza periférica. Há aí uma crítica e uma constatação do declínio de Lisboa como centro mercantil da nação portuguesa, o olhar do narrador mira aquelas e aqueles que habitam as bordas

${ }^{2}$ SIDA é a abreviação utilizada em Portugal para a Síndrome da Imunodeficiência Adquirida. 
do decadente império colonizador. Os símbolos e elementos do ser português - ser homem, ser branco, ser heterossexual, ser cristão - são apresentados como anacrônicos frente às vidas dessas personagens espalhadas na periferia. A natureza palimpséstica de tais símbolos no mundo atual se revela através de um narrador que ressalta como as pessoas que vivem na Portugal de hoje não se encaixam em espaço algum (LOPES, 2018, p. 114), apenas perambulam nas ruínas de um suposto grande passado.

E o que é a doença senão também uma borda entre a vida e a morte? Habitantes das bordas todas e todos que escapam dessa restrita definição de humano dominante. O que traz a pergunta: qual a importância da doença dentro da narrativa de Última Paragem Massamá? A doença de Lucas não é uma doença qualquer, a SIDA, ou como conhecemos no Brasil, a aids, explode na narrativa sem causar o grande impacto prenunciado, pois sim há um prenúncio de sua chegada, mas quando ela finalmente chega, a velocidade da narrativa parece aumentar e a doença é vivida nas páginas de forma ligeira, quase inconsequente e indolor para o maior afetado. Ao que Lucas adoece, o narrador se afasta dele, a aproximação, que havia se dado nos capítulos nos quais a história de Lucas e João é narrada, relação que de antemão sabemos levará ao adoecimento, se esvai no momento em que a contração do vírus acontece. Testemunha-se um narrador que questiona seu personagem "Quais são os teus projectos, Lucas, além da febre, dos vómitos, do morrer aqui a nada?" (VIEIRA, 2011, p. 171).

E então entramos no mundo de Vanessa, de Vanessa percebendo a vida, Lucas na sua vida, a raiva por Lucas não mais estar lá e caminhando para a morte: o livro acaba. A doença parece ficar em suspenso e a história acaba quando Vanessa acaba. João é abandonado pelo narrador, Lucas míngua num hospital, o narrador parece também o afastar. Não há grandes elaborações sobre a reação de Lucas ou uma mirada ao seu mundo interior. Nem no de João.

$\mathrm{O}$ que esse distanciamento significa? Novamente, qual a importância da SIDA em Última Paragem Massamá? Em entrevista na época do lançamento do livro Pedro Vieira diz: “[Eu] quis contar uma tragédia, nada melhor do que fazer a ponte com o período clássico e com a história de um homem, Varo, que cometeu suicídio quando o destino lhe escapou das mãos. 
Tal como sucede com a minha Vanessa" (VIEIRA, 2011, n.p.). Deduz-se da fala do autor que a tragédia do romance não é Lucas contraindo a SIDA e sim Vanessa perdendo seu destino, a seguridade da vida normal que Lucas representa e materializa. A doença é mais do que um fato que acontece a Lucas, ela é um acontecimento que dilacera a suposta normalidade e seguridade da vida marital heterossexual num subúrbio português. E a doença entra nesse mundo, pelo qual Vanessa estava disposta a tudo para mantê-lo intacto, através da homossexualidade. A vida heterossexual, que deveria representar a segurança e deveria ser sólida, é revelada subitamente frágil.

$\mathrm{O}$ vírus revela essa fragilidade por meio do tropo desgastado que conflagra homossexualidade com promiscuidade e doença moral e, então, física. Uma escolha perigosa do autor. Existe sim uma singela união entre João e Vanessa no final da narrativa, de possíveis inimigos e representantes de mundos distintos a parceiros no cuidado de Lucas, que pode ser considerada como elemento amenizador do impacto simbólico de se apresentar a dissolução de pessoas, laços e da própria teia do cotidiano como resultado da prática homossexual de Lucas. O que não surpreende, pois Vanessa também nunca foi a mulher ideal casta, a vida com Lucas era uma tentativa de subir a um patamar de normalidade para ela. A existência de Vanessa em essência tão frágil quanto a de Lucas, de João e todo o amálgama de personagens que Pedro Vieira oferece nas partes iniciais da narrativa, todos demonstrando que, na verdade, vivem nessa borda perene entre a manutenção de um cotidiano a linha de Sintra, o sacolejar do trem, o voltar e ir ao trabalho, os rostos conhecidos e cansados - e a possibilidade de um passo em falso desestabilizar tudo, ou pior, extinguir pessoas e vidas e ainda assim não desestabilizar nada, o que acontece quando o máximo que a suposta morte de Vanessa na linha do trem causa aos passageiros é um pequeno atraso numa manhã qualquer de trabalho.

Porém, é de extrema relevância que o passo em falso de Lucas seja uma relação homossexual que o leva à SIDA. O peso simbólico dessas imagens precisa ser revisitado. Como aponta Marcelo Bessa na introdução do livro Histórias Positivas - a literatura (des)construindo a AIDS (BESSA, 1997, p. 12), temos nessa doença uma particularidade de enorme importância, a epidemia da hiv/aids é mais do que uma questão biomédica, é uma construção 
discursiva. O discurso que constrói o imaginário da hiv/aids e que possui papel central em como serão tratados e, na maioria das vezes, estigmatizados os infectados, é notavelmente um braço do discurso patologizador da homossexualidade, seja como doença moral ou como doença física. A crise da aids surge então como possibilidade de reforço desses discursos, utilizando homossexuais infectados como prova de uma suposta degeneração. A escolha do autor por essa doença insere o romance na teia discursiva da aids e da homossexualidade, pois, se "a AIDS é uma construção plural, se é uma teia discursiva, o fio literário se enreda (e, necessariamente, deve se enredar) com outros dessa mesma teia" (BESSA, 1997, p. 13).

O primeiro caso de hiv/sida foi registrado em 1983 em Portugal, apenas um ano depois do ciclo de debates "Ser (Homo)sexual", considerado o primeiro evento de proporções nacionais, que acontece no Centro Nacional de Cultura em Lisboa. Segundo o histórico traçado por Ana Cristina Santos, após eventos e momentos dispersos marcantes nos anos 80, é apenas nos 90 que um ativismo gay se organiza de forma mais ativa em solos lusitanos (SANTOS, 2002, p. 597). É necessário lembrar que esse é um país com fortes influências judaico-cristãs e com uma concepção de família patriarcal nuclear como norma fortemente atrelada ao sentimento de nação e de constituição de um povo. A epidemia da SIDA começa apenas nove anos depois do 25 de abril e da redemocratização portuguesa e explode em um momento de incipiente organização do movimento gay, que logo se depara com uma nova e potente fonte de estigmatização. Em 2001, Portugal era considerado o país da Europa com o maior número de casos de hiv, de acordo com o Relatório "Portugal Infeção VIH/SIDA em números", publicado em 2013 com dados referentes aos anos de 2007 a 2011. No ano de publicação de Última Paragem Massamá, 2011, mil oitocentas e vinte duas pessoas foram infectadas no país, a maioria heterossexual.

Como aponta Santos, tanto a homossexualidade como o adultério são consideradas abominações pela maioria da população religiosa portuguesa (SANTOS, 2002, p. 600). Pedro Vieira une os dois: em um ato de traição Lucas se relaciona com um homem. A presença da religião no romance é constante, principalmente através de alusões e referências quase cômicas, estabelecendo a posição do narrador como alguém alheio aos dogmas cristãos 
ao ponto de zombar deles e não compartilhar seus valores. “[...] um funcionário público a fazer as vezes do cordeiro de Deus que tira o pecado do mundo, ou que pelo menos o alivia, [...]" (VIEIRA, 2011, p. 112). Assim o narrador se refere a um Lucas prestes a sair escondido para encontrar João. É um narrador que escolher rir de todo habitualmente central e certo da cultura portuguesa e escolhe se aproximar das bordas e dar a quem lá está sua atenção, ainda que de passagem. Desde esse local, pode-se supor que a posição também irônica e descrente quanto às relações estabelecidas pelas personagens também provenha da desestabilização de tudo que se diz sagrado. O autor profana, no sentido proposto por Giorgio Agamben, aquilo que era reservado a poucos, trazendo descrições das vidas dissidentes dos habitantes das margens por vezes através de imagens sarcasticamente lúcidas do catolicismo, da família e de uma certa absolvição da doença antes reservada a deus; ele as "restitui ao uso comum" (AGAMBEN, 2007, p. 65). Essas considerações evocam o questionamento inicial acerca de qual o papel do hiv em Última Paragem Massamá.

Em seu livro A Doença como Metáfora, publicado em 1978, ou seja, antes da crise da aids, Susan Sontag escreve sobre o uso de doenças fisiológicas, ou seja, que afetam o corpo material, como metáfora para outras coisas, como acontecimentos sociais, econômicos e políticos, estados espirituais, relações morais, etc. Sua posição é basicamente de crítica a essa metaforização que desumaniza, estigmatiza e molda a percepção social da pessoa adoecida, influenciando as políticas públicas de saúde e as posturas médicas das quais está dependente. Desde a doença como punição divina, como desequilíbrio do corpo que evidencia um desequilíbrio da pólis, até como ferramenta retórica para denunciar os problemas sociais utilizada por pessoas de diferentes posições políticas, observa-se o entrecruzar de discursos variados que se interpelam e criam verdadeiras mitologias ao redor das doenças. O doente, no caso de Lucas, o infectado por hiv, é uma metáfora ambulante dentro da narrativa. Talvez um abuso proposital do clichê. Homem heterossexual trai sua namorada com outro homem, contrai o vírus e morre. Mas qual o ônus do emprego de uma imagem desse porte? Susan Sontag escreve em 1988, dez anos após a publicação de $A$ Doença como Metáfora sobre a aids: 
No caso da aids, a vergonha está associada à atribuição de culpa, e o escândalo nada tem de obscuro. [...] Não se trata de uma doença misteriosa que escolhe suas vítimas de modo aparentemente aleatório. De fato, contrair aids equivale precisamente a descobrir - ao menos na maioria dos casos até agora - que se faz parte de um determinado "grupo de risco", uma comunidade de párias. A doença expõe uma identidade que poderia ter permanecido oculta dos vizinhos, colegas de trabalho, familiares e amigos. Ao mesmo tempo, confirma uma identidade, e, no grupo de risco mais atingido nos Estados Unidos num primeiro momento, o dos homossexuais masculinos, chegou a dar origem a uma comunidade, bem como a uma experiência que isola e expõe os doentes a discriminações e perseguições (SONTAG, 1988, p. 51).

Para Lucas contrair hiv significa exatamente isso, expor uma identidade, ou melhor, uma prática. Expor a hipocrisia da sociedade da qual não só faz parte, mas também continua a construir. Afinal, seus encontros com João são encobertos por uma mentira deveras clichê: João é transformado no colega Fontes da repartição e os encontros do casal são assim comunicados à Vanessa: “[...] estamos a combinar arranjar um grupinho pra jogar futebol de salão." (VIEIRA, 2011, p. 97). Até mesmo depois da verdade ser revelada, Lucas continua a fingir arrumar a mochila esportiva antes dos encontros com João. Há um conforto nessa manutenção falsa das aparências na ordem heterossexual. A SIDA traz a verdade, a SIDA, até mesmo ao rasgar o tecido da normalidade, reconcilia os diversos mundos: são o mesmo mundo, é o mesmo mundo.

A doença como uma porta para o desvelamento de uma realidade oculta e de tabus culturais se faz presente em muitas obras, cruza o tempo e o espaço: A Montanha Mágica (1924) de Thomas Mann, A Redoma de Vidro (1963) de Sylvia Plath, $A$ Peste (1947) de Albert Camus, A Imaginária (1959) de Adalgisa Nery, Controle (2019) de Natália Borges Polesso, pode-se continuar essa lista por páginas e páginas. Não causa surpresa que muitas dessas narrativas listadas possam ser consideradas romances de formação, o adoecimento funciona dentro delas como o corredor no qual os passos rumo a uma nova compreensão, agora não mais ingênua ou ludibriada, são dados. Tais 
romances engendram algo que Virginia Woolf descreve em seu ensaio $O n$ Being IIl (1930) como o poder confessional da doença:

Há, confessemos (e a doença é o grande confessionário) uma franqueza infantil na doença; coisas são ditas, verdades que a respeitabilidade cautelosa da saúde esconde são reveladas. Acerca da simpatia, por exemplo, nós podemos viver sem ela. Essa ilusão de um mundo tão perfeitamente organizado que cada gemido ecoa, de seres humanos amarrados tão juntos por necessidades e medos em comum que a fisgada no pulso de um sente-a o outro, no qual não importa o quão estranha sua experiência, outros também a tiveram, no qual não importa o quão longe você viajou em sua mente, outros lá já estiveram antes de você - é tudo uma ilusão. Nós não conhecemos nossas próprias almas, imagine as almas dos outros. Seres humanos não andam de mãos dadas por todo o caminho. [...] Na doença esse fingimento acaba (WOOLF, 1964, p. 17, tradução nossa). ${ }^{3}$

Última Paragem Massamá, no entanto, não é um romance que apresenta a trajetória de um personagem que adoece e suas reverberações na auto percepção e percepção do mundo. Como apontado anteriormente, a doença é o culminar de uma sequência de episódios, os quais, por final, levam a uma suspensão da vida e de qualquer pensamento sobre ela. Tal negação a oferecer grandes fechamentos e lições morais sofisticadas aos leitores pode ser lida como um dos muitos traços pós-modernos que caracterizam o romance, traços que questionam os conceitos humanistas liberais, como a continuidade, a homogeneidade, a origem, a certeza, de forma a "indagar [a relação do romance] com a experiência." (HUTCHEON, 1991, p. 84). Essa indagação se faz pelo abuso dos clichês: a religião cristã, a família nuclear patriarcal, o universo do trabalho e a própria nação perdem sua solidez

\footnotetext{
3 "There is, let us confess it (and illness is the great confessional) a childish outspokenness in illness; things are said, truths blurted out, which the cautious respectability of health conceals. About sympathy for example; we can do without it. That illusion of a world so shaped that it echoes every groan, of human beings so tied together by common needs and fears that a twitch at one wrist jerks another, where however strange your experience other people have had it too, where however far you travel in your own mind someone has been there before you - is all an illusion. We do not know our own souls, let alone the souls of others. Human beings do not go hand in hand the whole stretch of the way. [...] In illness this make-believe ceases." (WOOLF, 1964, p. 17).
} 
através da voz do narrador. O rasgo na realidade, que denuncia a decadência de tudo que parecia ser basal, é o rasgo operado tanto pela homossexualidade, que parece, no entanto, não ser suficiente para que Lucas opere ele mesmo tal quebra, e, finalmente, pela aids.

Como disse Virginia Woolf, a doença carrega consigo a força de libertação das verdades que o mundo da saúde e dos saudáveis parece não ver (WOOLF, 1964, p. 17) e, talvez, seja essa a função da aids em Última Paragem Massamá. Não uma metáfora da decadência e destruição de um homem através da homossexualidade, mas uma metáfora da decadência e destruição de uma sociedade hipócrita. É imprescindível notar um certo anacronismo da visão cultural acerca da síndrome no romance, o que a transforma em mais um elemento que remete ao clichê como crítica. A imagem do portador do vírus cadavérico e à beira da morte, quiçá tenha sido superada, tanto por conta dos desenvolvimentos dos tratamentos, muito mais efetivos desde os anos 2000, quanto pelo desgaste - a repetição dessa imagem ela mesma banaliza, por uma espécie de adormecimento do choque em ver outro ser humano em tal condição, a necessidade da representação aids - é substituída pela imagem da cura e do coquetel (INÁCIO, 2016, p. 483). Contudo, ainda assim, o autor escolhe a imagem supostamente ultrapassada: Lucas trai Vanessa com João, contrai o vírus em uma orgia homossexual, definha e a leitora despede-se dele na iminência de sua morte. Porém, João, o homossexual assumido, sai incólume, quase como se, por habitar sua vida abertamente, sem esconderijos e mentiras absurdamente banais, ele não precisasse da doença para desvelar nada.

A tragédia do livro, como já admite o autor, é exatamente a fragilidade com que a tessitura da vida se despedaça e até mesmo o final é inconclusivo, nem mesmo essa tragédia se completa: a leitora não tem certeza se Lucas de fato morre, apesar de parecer impossível que sobreviva, e também não tem certeza se Vanessa morre, apesar de parecer também impossível que sobreviva. A última sentença do romance profana até a tragicidade do suicídio: “[...] caso contrário ainda falhar o objetivo, quem sabe continuas viva e com ambas as pernas amputadas, em homenagem ao teu duplo fracasso. $\mathrm{Na}$ vida como na morte." (VIEIRA, p. 207, 2011). Mas tudo isso é o correr da vida, talvez nessa continuidade esteja algum tipo de redenção: assim era no Império 
Romano, cenário da história paralela que acompanha cada capítulo do livro, assim é na Portugal de Vieira. No entanto, João, sai incólume.

\section{Referências}

AGAMBEN, Giorgio. Profanações. Tradução de Selvino J. Assmann. São Paulo: Boitempo, 2007.

BESSA, Marcelo. Histórias positivas: a literatura (des)construindo a AIDs. Rio de Janeiro: Record, 1997.

Direção Geral de Saúde. Portugal - Infeção VIH/SIDA e Tuberculose em números - 2013. Lisboa: 2013. Disponível em: https://www.dgs.pt/estatisticas-de-saude/estatisticas-de-

saude/publicacoes/portugal-infecao-vihsida-em-numeros-2013-pdf.aspx.

Último acesso em 07 jul 2020.

HUTCHEON, Linda. Poética do pós-modernismo. História - Teoria - Ficção. Tradução de Ricardo Cruz. Rio de Janeiro: Imago, 1991. Disponível em: http://www.letras.puc-

rio.br/unidades\&nucleos/catedra/revista/4Sem_02.html.

INÁCIO, Émerson da Cruz. Carga zerada: HIV/AIDS, discurso, desgaste, cultura. Em: Via Atlântica 29, FFLCH/USP, 2016. Disponível em: http://www.revistas. usp. br/viaatlantica/article/view/118885 . Último acesso em 17 jul 2020.

INÁCIO, Émerson da Cruz. Outros barões assinalados: a emergência do discurso gay na produção literária portuguesa contemporânea. Em: Anais do VIII Congresso Luso-Afro-Brasileiro de Ciências Sociais, Coimbra, 2004. Disponível em: https://www.ces. uc.pt/lab2004/inscricao/pdfs/grupodiscussao2/EmersonIn acio.pdf. Acesso em: 17 jul. 2020.

LOPES, Luís Pimenta. Um camarote para a CRIL: Suburban Spaces and Transculturality in Pedro Vieira's última Paragem Massamá. Em: PRATA, A. F.; WIESER, D. Eds. Cities of the Lusophone World: Literature, Culture and Urban Transformations. Oxford: Peter Lang, 2018, p. 113-131.

Observatório da discriminação em função da orientação sexual e identidade de género. Números da Violência contra as Pessoas LGBT - 2013. Portugal: $2014 . \quad$ Disponível em: https://ilgaportugal.pt/noticias/Noticias/relatorioOBSERVATORIOlgbt.pdf. Acesso em: 7 jul. 2020.

RAMOS, Diego Rogério. Composições enfermas - doença, crítica e música em Thomas Mann. Em Kriterion, Belo Horizonte, v. 59, n. 139, p. 109-132, 2018. Disponível 
http://www.scielo.br/scielo.php?script=sci_arttext\&pid=S0100512X2018000100109\&lng=en\&nrm=iso. Acesso em: 14 jul. 2020.

SANTOS, Ana Cristina. Sexualidades politizadas: ativismo nas áreas da AIDS e da orientação sexual em Portugal. Cad. Saúde Pública, Rio de Janeiro, v. 18, n. 3, p. 595-611, 2002. Disponível em: http://dx.doi.org/10.1590/S0102311X2002000300004. Acesso em: 5 jul. 2020.

SILVA, Carlos Roberto da. A estetização da doença na ficção de Lúcio Cardoso. Tese (Doutorado em Estudos Literários) - Faculdade de Letras. Universidade Federal de Minas Gerais. Belo Horizonte, 2016. Disponível em: http://hdl. handle. net/1843/ECAP-A7GNNQ. Acesso em: 14 jul. 2020.

SONTAG, Susan. Doença como metáfora / AIDS e suas metáforas. Rio de Janeiro: Cia das Letras, 2007.

TONIETTI, Marcelo Augusto. Um breve olhar histórico sobre a homossexualidade. Revista Brasileira de Sexualidade Humana, v. 17, n. 1, p. 4152, $2006 . \quad$ Disponível em: http://pessoal.educacional.com.br/up/4660001/9842654/Revista\%20Brasileir a\%20de\%20Sexualidade\%20Humana\%20-\%20volume\%2017.pdf\#page=37.

Acesso em: 17 jul. 2020.

VIEIRA, Pedro. "É condição da liberdade ser uma coisa transitória, ou que tem de ser sempre alimentada". Entrevista a Mario Rufino. Shifter, 21 de maio de 2019. Disponível em: https://shifter.sapo.pt/2019/05/pedro-vieira-mare-altaentrevista/ Acesso em: 17 jul. 2020.

VIEIRA, Pedro. "Quis fazer uma espécie de neo-realismo travestido." Entrevista concedida a Hélder Beja. Parágrafo, Suplemento Literário do Jornal Ponto final, Macau, 2011. Disponível em https://paragrafopontofinal.wordpress.com/2011/05/13/\%E2\%80\%9Cquisfazer-uma-especie-de-neo-realismo-travestido\%E2\%80\%9D/. Acesso em 05 jul 2020.

VIEIRA, Pedro. Última Paragem Massamá. Lisboa: Quetzal Editores, 2011.

WOOLF, Virginia. The moment and other Essays. London: Hogarth Press, 1964.

Recebido em 31 de Agosto de 2020.

Aceito em 30 de outubro de 2020. 